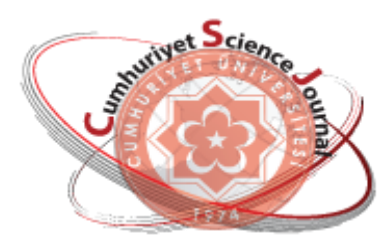

e-ISSN: $2587-246 X$

ISSN: $2587-2680$

\section{Cumanoriyet Seienee Journal \\ $\cos$}

Cumhuriyet Sci. J., Vol.38-3 (2017) 502-506

\title{
Photonuclear Reaction Results of Energy Levels of Iodine Isotopes
}

\author{
Murat AYGUN ${ }^{1 *}$, Alp CESUR ${ }^{2}$, Mahmut DOGRU ${ }^{1}$, Ismail BOZTOSUN ${ }^{2}$, Muhammed KANARYA ${ }^{1}$, \\ Muhammed Fatih KULUOZTURK ${ }^{3}$, Sultan SAHIN BAL ${ }^{1}$, Sule KARATEPE ${ }^{4}$ \\ ${ }^{I}$ Bitlis Eren University, Department of Physics, Bitlis, Turkey \\ ${ }^{2}$ Akdeniz University, Department of Physics, Antalya, Turkey
}

${ }^{3}$ Bitlis Eren University, Department of Electrical and Electronics Engineering, Bitlis, Turkey

${ }^{4}$ Bitlis Eren University, Vocational School of Hizan, Bitlis, Turkey

\begin{abstract}
In this study, photonuclear reaction of ${ }^{127} \mathrm{I}$ has been studied by using bremsstrahlung photons of 18 $\mathrm{MeV}$ endpoint energy via a clinical linear accelerator. As a result of this, ${ }^{127} \mathrm{I}(\gamma, \mathrm{n})^{126} \mathrm{I}$ and ${ }^{127} \mathrm{I}(\mathrm{n}, \gamma)^{128} \mathrm{I}$ reactions have been observed. The gamma photons emitted by the excited nuclei have been counted with an HPGe detector. The experimental data have been analyzed by using gf3 and ROOT spectrum programs and all the energy transitions have been calculated. The results have been compared with the literature values.
\end{abstract}

Keywords: Clinical linear accelerator, photonuclear reaction, ${ }^{126,127,128}$ I, energy levels

\section{İyot İzotoplarının Enerji Seviyelerinin Fotonükleer Reaksiyon Sonuçları}

Özet: $\mathrm{Bu}$ çalışmada, bir klinik lineer hızlandırıcı yardımıyla $18 \mathrm{MeV}$ maksimum enerjili bremsstrahlung fotonları kullanılarak ${ }^{127} \mathrm{I}$ fotonükleer reaksiyonu çalışıldı. Bunun bir sonucu olarak, ${ }^{127} \mathrm{I}(\gamma, \mathrm{n}){ }^{126} \mathrm{I}$ ve ${ }^{127} \mathrm{I}(\mathrm{n}, \gamma){ }^{128} \mathrm{I}$ reaksiyonları gözlemlendi. Uyarılmış çekirdekler tarafından yayımlanan gamma fotonları bir HPGe detektör ile sayıldı. Deneysel data gf3 ve ROOT spektrum programları kullanılarak analiz edildi ve tüm enerji geçişleri hesaplandı. Sonuçlar literatür değerleriyle karşılaştırıldı.

Anahtar Kelimeler: Klinik lineer hızlandırıc1, fotonükleer reaksiyon, ${ }^{126,127,128}$ I, enerji seviyeleri

\section{INTRODUCTION}

Nuclear reaction is an important tool to examine properties of nucleus. It is well-known that there are different reaction types such as elastic scattering, inelastic scattering, quasielastic scattering, transfer reaction, breakup and knockout. Photonuclear reaction is one of these nuclear reactions. It is an interaction between nucleus and photon in the general sense. Photonuclear reaction is very important to understand the structure and dynamics of the atomic nucleus [1].
In the present day, different methods to study nuclear reactions are available. The clinical linear accelerator (cLINAC) is one of them and has attracted much attention in nuclear physics experiments in recent years [2-3]. Mohr et al. [4] have performed ${ }^{197} \mathrm{Au}(\gamma, \mathrm{n}){ }^{196} \mathrm{Au}$ reaction by using a cLINAC. They have reported that the cLINACs are a perfect photon source for photonuclear experiments. Boztosun et al. [5-6] have been measured the subsequent transition energies and half-lives of zinc isotopes via photonuclear reactions. Aygun et al. [7] have reported the energy 
levels of ${ }^{92 \mathrm{~m}} \mathrm{Nb}$ with the help of photonuclear reaction. In this context, to see the applicability of cLINACs for different nuclei would be interesting and useful when it is considered that the number of cLINACs is increasing every passing day.

In the present work, our aim is to study Iodine (I) element, measure the energy levels of product nuclei, and increase the applicability of clinical linacs in experimental nuclear physics. It has 39 isotopes from ${ }^{107} \mathrm{I}$ to ${ }^{145} \mathrm{I}$, which its stable isotope is approved as ${ }^{127} \mathrm{I}$. The isotopes of I element are widely used for the purposes of research, diagnosis and treatment in field of nuclear medicine [8]. For example, ${ }^{125} \mathrm{I}$ is used as a radioisotope in radiation therapy [9]. ${ }^{128}$ I can be utilized in diagnostics researches with a significant reduction of radiation dose [10]. In this respect, various studies can be found in the literature [11-14].

In the next section, the experimental details are given. The results and discussion of the experiment are conducted in Section 3. Section 4 is devoted to summary and conclusion.

\section{EXPERIMENTAL DETAILS}

In the irradiation experiment, we have used a clinical LINAC (Elekta TM Synergy TM accelerator) [15]. It can be operated as a bremsstrahlung photon source. To form the primary electron beam, an electron gun with an energy of about $50 \mathrm{keV}$ is used. The average beam current of the cLINAC is $30 \mu \mathrm{A}$ for an electron energy about $18 \mathrm{MeV}$. The electron beam is impinged on the tungsten target with a thickness of $3.5 \mathrm{~mm}$ which stops the electrons and produces photon as bremsstrahlung photons.

In the experimental process, the sample has been placed $0.56 \mathrm{~m}$ away from the target, which the process is shown in Figure 1. The sample with 99.99\% purity (metals basis) has been procured from the ACI ALLOYS Company in an airtight container. The sample in powder was placed into a $40 \times 10 \times 10 \mathrm{~mm}^{3}$, made of glass with a wall thickness of $0.0017 \mathrm{~m} .{ }^{127} \mathrm{I}$ has been exposed to sufficient energetic bremsstrahlung photons obtained by using the cLINAC. The irradiation time of the sample is about $35 \mathrm{~min}$. Then, the sample has been placed into the detector. The detector used in this work is a high-purity germanium detector (HPGe).

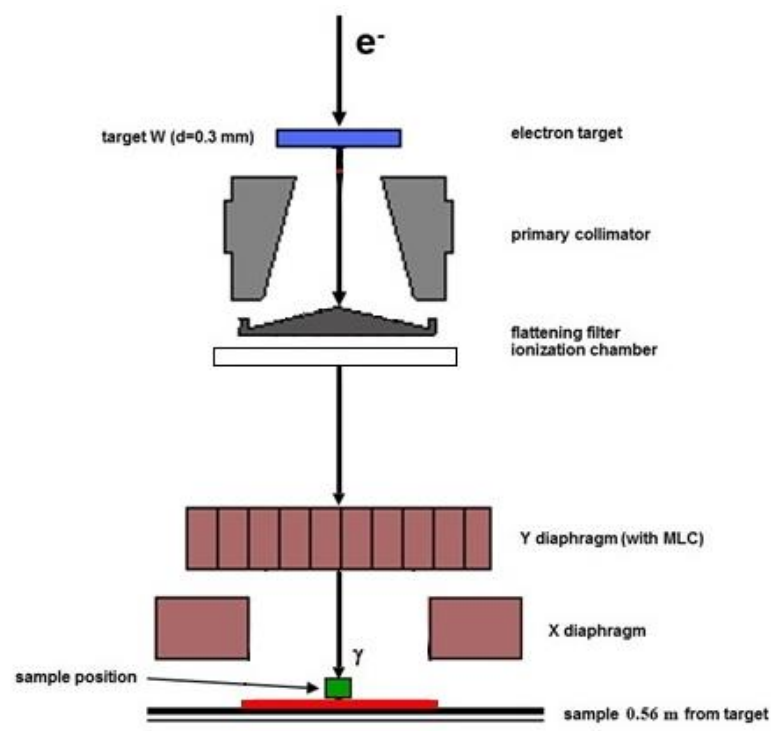

Figure 1. Schematic view of the cLINAC setup used for irradiation of ${ }^{127}$ I sample.

The calibration of the detector system has been provided with two sets of sources. Firstly, the point sources contained the isotopes such as ${ }^{22} \mathrm{Na},{ }^{54} \mathrm{Mn}$, ${ }^{57} \mathrm{Co},{ }^{60} \mathrm{Co},{ }^{109} \mathrm{Cd},{ }^{133} \mathrm{Ba}$ and ${ }^{137} \mathrm{Cs}$ isotopes supplied by the Çekmece Nuclear Research and Training Center (IAEA 1364-43-2) have been used. Secondly, a soil sample provided by the Turkish Atomic Energy Authority (TAEK) has been evaluated. It involved different natural radioactive isotopes such as ${ }^{40} \mathrm{~K},{ }^{226} \mathrm{Ra}$ and ${ }^{232} \mathrm{Th}$ with known activities. In calibration with this sample, only the strongest peaks have been used.

The gamma photons emitted with the decay have been counted by using an HPGe detector. To determine the gamma energy values of the decay, gf3 and ROOT spectrum analysis programs [16-17] have been applied to the data taken from MAESTRO32 software [18]. More detailed information about the data analysis procedure can be found in the previous studies [6]. 


\section{RESULTS AND DISCUSSION}

${ }^{127}$ I irradiated with bremsstrahlung photons turns into ${ }^{126} \mathrm{I}$ emitting a neutron, and the reaction is in the following form

$$
{ }^{127} \mathrm{I}+\gamma \rightarrow{ }^{126} \mathrm{I}+\mathrm{n}
$$

We have listed six energy transitions measured with this study in Table 1.

Table 1. Gamma-ray energies obtained in the decay of ${ }^{126} \mathrm{I}$ in comparison with the literature.

\begin{tabular}{ccc}
\hline $\begin{array}{c}\text { Our results } \\
(\mathrm{keV})\end{array}$ & $\begin{array}{c}\text { The results of Ref. [19] } \\
(\mathrm{keV})\end{array}$ & $\begin{array}{c}\text { The results of Ref. [20] } \\
(\mathrm{keV})\end{array}$ \\
\hline $388.640 \pm 0.011$ & $388.633 \pm 0.011$ & 388.63 \\
$491.268 \pm 0.014$ & $491.243 \pm 0.011$ & 491.24 \\
$666.345 \pm 0.020$ & $666.331 \pm 0.012$ & 666.33 \\
$753.841 \pm 0.024$ & $753.819 \pm 0.013$ & 753.82 \\
$879.867 \pm 0.037$ & $879.876 \pm 0.013$ & 879.88 \\
$1420.151 \pm 0.072$ & $1420.19 \pm 0.03$ & 1420.17 \\
\hline
\end{tabular}

We have displayed the gamma-ray spectrum of ${ }^{127} \mathrm{I}$, without background subtraction, in Figure 2. To define the compatibility of our results, we have conducted a comparative study with the literature [19-20]. When our results have been compared with the results of both Katakura and Kitao [19] and Jackson and Meyer [20], we have observed that our transition energies are in very good agreement with the literature.
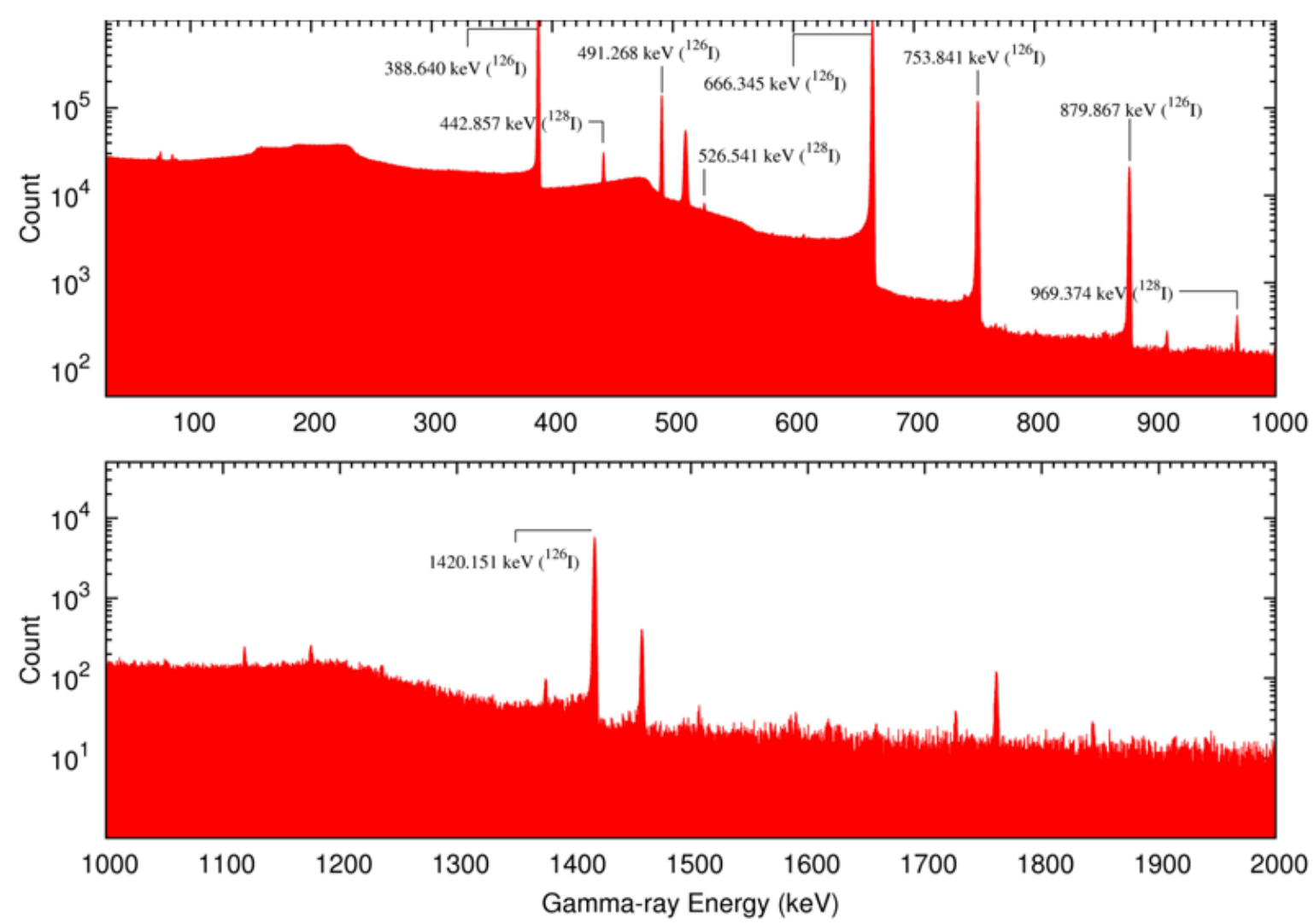

Figure 2. An irradiated ${ }^{127}$ I spectrum with bremsstrahlung end-point energy of $18 \mathrm{MeV}$ without background subtraction. 
Neutron capture reaction can take place when a cLINAC has been used in the photonuclear reaction. This case occurs when neutrons emitted from the tungsten target interact with ${ }^{127} \mathrm{I}$. The reaction is written as

$$
{ }^{127} \mathrm{I}+\mathrm{n} \rightarrow{ }^{128} \mathrm{I}+\gamma
$$

This case is not our main aim in the present study. However, we have calculated the energy transitions for this reaction and have given the gamma energy levels in Table 2. Also, we have shown the gammaray spectrum in Figure 2. When we have compared our results with the literature [21], we have noticed that our results are in fairly well agreement with the results of Ref. [21], especially for $526.541 \mathrm{keV}$.

Table 2. The same as Table 1 but for ${ }^{128} \mathrm{I}$ decay.

\begin{tabular}{cc}
\hline $\begin{array}{c}\text { Our results } \\
(\mathrm{keV})\end{array}$ & $\begin{array}{c}\text { The results of Ref. [21] } \\
(\mathrm{keV})\end{array}$ \\
\hline $442.857 \pm 0.030$ & $442.901 \pm 0.010$ \\
$526.541 \pm 0.034$ & $526.557 \pm 0.014$ \\
$969.374 \pm 0.057$ & $969.458 \pm 0.020$ \\
\hline
\end{tabular}

\section{SUMMARY AND CONCLUSION}

In this study, we have measured the energy transitions of ${ }^{126} \mathrm{I}$ and ${ }^{128} \mathrm{I}$ nuclei with bremsstrahlung photons of $18 \mathrm{MeV}$ endpoint energy obtained from a clinical linear accelerator. We have compared our results with the literature values. We have observed that our experimental results are in good agreement with the literature.

In the present work, we have also shown the suitability, achieve results and benefit for some isotopes of iodine element of a clinical linear accelerator in experimental studies of nuclear physics. We think that to see the applicability of clinical LINACs for different element or its isotopes would be interesting and useful.

\section{ACKNOWLEDGEMENTS}

We acknowledge the financial support of Bitlis Eren University Scientific Research Projects Coordination Unit (BEBAP) with a project grant number 2014.03.

\section{REFERENCES}

[1]. Kaplan, A., Özdoğan, H., Aydın, A., Tel, E., 2012. Photo-neutron Cross Section Calculations of Several Structural Fusion Materials. J. Fusion Energ. 32, 344-349.

[2]. Bayram T., Akkoyun S., Uruk S., Dapo H., Dulger F., Boztosun I., 2016.Transition energy and half-life determinations of photonuclear reaction products of erbium nuclei. International Journal of Modern Physics E: Nuclear Physics 25, 1650107.

[3]. Akkoyun S., Bayram T., Dulger F., Djapo H., Boztosun I., 2016. Energy level and halflife determinations from photonuclear reaction on Ga target. International Journal of Modern Physics E: Nuclear Physics, 25, 1650045.

[4]. Mohr, P., Brieger, S., Witucki, G., Maetz, M., 2007. Photoactivation at a clinical LINAC: The ${ }^{197} \mathrm{Au}(\gamma, \mathrm{n}){ }^{196} \mathrm{Au}$ reaction slightly above threshold. Nucl. Instr. and Meth. A 580, 1201-1208.

[5]. Boztosun, I., Dapo, H., Özmen, S.F., Çeçen, Y., Karakoç, M., Çoban, A., Cesur, A., Caner, T., Bayram, E., Keller, G.B., Küçük, B., Guvendi, A., Derman, M., Kaya, D., 2014. The results of the first photonuclear reaction performed in Turkey: the zinc example. Turk. J. Phys. 38, 1-9.

[6]. Boztosun, I., Dapo, H., Karakoç, M., Özmen, S.F., Çeçen, Y., Çoban, A., Caner, T., Bayram, E., Saito, T.R., Akdoğan, T., Bozkurt, V., Kuçuk, Y., Kaya, D., Harakeh, M.N., 2015. Photonuclear reactions with zinc: A case for clinical linacs. Eur. Phys. J. Plus 130, 185.

[7]. Aygun, M., Cesur, A., Dogru, M., Boztosun, I., Dapo, H., Kanarya, M., Kuluozturk, M.F., Bal, S.S., Karatepe, S., 2016. Using a clinical linac to determine the energy levels of ${ }^{92 \mathrm{~m}} \mathrm{Nb}$ via the photonuclear reaction. Appl. Radiat. Isot. 115, 97-99.

[8]. Dzhilavyan, L.Z., Karev, A.I., Raevsky, V.G., 2011. Possibilities for the production of radioisotopes for nuclear-Medicine 
problems by means of photonuclear reactions. Phys. At. Nuc. 74, 1690-1696.

[9]. Muljadi, P., 2012. Ioine, (Unpublished).

[10].Maruyama, Y., Kazuhide, I., 1967. Production of iodine-128 by small research reactor. J. Nucl. Sci. Tech. 4, 565-569.

[11].Mulvey, P.F., Jr., Cardarelli, J.A., Meyer, R.A., Cooper, R., Burrows, B.A., 2012. Sensitivity of bremsstrahlung activation analysis for iodine determination. Proceedings of the symposium on radioisotope sample measurement techniques in medicine and biology held by the international atomic energy agency in Vienna, 24-28 May (1965).

[12].Mandal, S., Mandal, A., Lahiri, S., 2012. Separation of nca ${ }^{123,124,125,126}$ I from alpha particle induced the natural antimony trioxide target. J. Nucl. Sci. Tech. 292, 579584.

[13].Kuo, C.L., Tsai, T.L., Chiang, A.C., ChangLiao, K.S., Chao, J.H., 2013. Determination of ${ }^{129} \mathrm{I}$ in cement-solidified radwastes using neutron activation. J. Nucl. Sci. Tech. 298, 465-473.

[14].Fan, Y., Hou, X., Zhou, W., 2013. Progress on ${ }^{129} \mathrm{I}$ analysis and its application in environmental and geological researches. J. Nucl. Sci. Tech. 321, 32-46.

[15].Elekta, Elekta digital accelerator, Technical training guide, https://www.elekta.com/services/educationand-training.html

[16].Radford, D.C., 1995. ESCL8R and LEVIT8R: Software for interactive graphical analysis of HPGe coincidence data sets. Nucl. Instr. and Meth. A 361, 297.

[17].Brun, R., Rademakers, F., 1997. ROOT: An object oriented data analysis framework. Nucl. Instr. and Meth. A 389, 81-86.

[18].Maestro, http://pdf.directindustry.com/pdf/ortec/a65b32-maestro-32-mcaemulationsoftware/50423-143327.html

[19].Katakura, J., Kitao, K., 2002. Nuclear Data Sheets for $\mathrm{A}=126$. Nuclear data sheets 97 , 765-926.

[20].Jackson, S.V., Meyer, R.A., 1977. Population of $0^{+}$states in ${ }^{126} \mathrm{Te}$ by decay of ${ }^{126} \mathrm{I}$ and softness in even-even Te nuclei. Phys. Rev. C 15, 1806.

[21].Kanbe, M., Kitao, K., 2001. Nuclear Data Sheets for $A=128$. Nuclear data sheets 94 , 227. 